\title{
EDITORIAL
}

\section{Better outcomes for depressive disorders? ${ }^{1}$}

Well conducted investigations into the long-term outcome of depressive disorders are rare. This issue of Psychological Medicine publishes two important papers reporting on different cohorts of depressed patients, one series from Japan (Kanai et al. 2003) and the other from Cambridge UK (Kennedy et al. 2003). Both were ascertained in the early 1990s and have been followed for 5-6 and 8-10 years respectively. Each study demonstrates methodological advances. Both invite comparison with previous reports of the long-term outcome of depression whose follow-up periods span the last 40 years. Is the outcome of depressive disorders at last improving in the era of modern treatments? Is this merely an artefact of better research methods, or does it also reflect therapeutic advances? If there has been very little improvement in some aspects of outcome, what lessons can we learn for future research and practice development?

\section{BACKGROUND}

Although Kraepelin (1921) identified the prognosis for an individual attack of depressive illness as favourable, he also warned of the probability that the disease would be repeated several times or even frequently. To clarify the magnitude of such risks he called for the follow-up of large numbers of cases throughout life, stating that this alone would settle the point. Paykel (1994) has reviewed the history of attempts to meet Kraepelin's challenge both in the pre-treatment era and thereafter. Early studies have been difficult to interpret because of methodological problems, and their gloomy findings of high levels of chronicity, recurrence and very poor global outcome have often been discounted as being due to bias from severe and already recurrent cases in asylum-based samples.

Following the introduction of effective treatments such as antidepressant medication in the late 1950s there was a growing air of optimism but very little long-term outcome research. The end of this age of innocence began with the publication of early results from the United States National Institute of Mental Health (NIMH) Collaborative Program on the Psychobiology of Depression (Keller et al. 1984), which followed a large cohort of mixed out-patients and in-patients referred with primary major depression to academic medical centres across the US. This was reinforced by the simultaneous publication of two long-term follow-up studies from London (Lee \& Murray, 1988) and Sydney (Kiloh et al. 1988), which described 15-18 year outcomes of consecutive depressed in-patients in University settings. All of these reports identified recurrence rates and poor long-term global outcomes that appeared to have changed little from the most pessimistic of earlier studies. They heralded a major reappraisal of the significance of an episode of severe depression and led to a re-framing of severe depressive illnesses as lifelong disorders more akin to hypertension or diabetes.

In reflecting on the experience of the NIMH follow-up, which eventually extended to 15 years, Keller \& Boland (1998) identify issues surrounding the need to develop better long-term maintenance treatments as amounting to a public health crisis. They write eloquently of recurrent depression as a pernicious and lifelong disorder, in which each episode engenders considerable costs for patients, their families and society.

1 Address for correspondence: Dr Alan S. Lee, Department of Psychiatry, B Floor, South Block, Queen's Medical Centre, Nottingham NG7 2UH. 


\section{BETTER FOLLOW-UP RESEARCH}

The NIMH, London and Sydney studies marked the beginning of a period of more highly developed follow-up methods. Advances over the past 25 years have included: (1) a growing understanding of the importance of comprehensive follow-up; (2) the use of actuarial methods such as survival analysis to allow for series attrition; (3) the use of standardized instruments for diagnosis, and standard definitions of change points such as recovery and recurrence; (4) follow through designs with repeated interviewing to minimize the problems of retrospective recall; and (5) attempts to avoid referral bias and ensure more representative series.

Kennedy et al. (2003) identify four studies published in the past 15 years that embody many of these advances and allow for exploration of possible temporal trends. These include the London, Sydney and NIMH investigations outlined above, and a report from Edinburgh (Surtees \& Barkley, 1994), which followed a predominantly in-patient cohort of depressed patients for 12 years.

\section{A GOOD OUTCOME GROUP?}

The Japanese study (Kanai et al. 2003) published in this issue also shows most of these methodological improvements. Most importantly, it moves us towards a less biased account of the natural history of moderate to severe depressive episodes, approximating more closely to the study of first episode cases representative of those referred to secondary psychiatric services from a catchment area population. Common sense suggests that outcomes will appear better as cohorts are ascertained with less bias towards more severe, recurrent cases with less complicating co-morbidity. As previous recurrence is a major predictor of future recurrence (see below), only the investigation of a first episode series can give a true picture of what can be expected by a patient presenting with a depressive illness for the first time.

Seventy-one per cent of the participants in the Japanese cohort were in their first episode compared with only $37 \%, 38 \%$ and $34 \%$ in the Edinburgh, NIMH and Cambridge cohorts respectively. This, as one might expect, is reflected in the lower 5 -year recurrence rates of $42 \%$ found in Japan as against $52 \%, 60 \%$ and $55 \%$ in Edinburgh, the NIMH cohort and Cambridge. Extrapolating the survival analysis curve from this study suggests that the life time recurrence risk for first-episodes of depression presenting to secondary mental health services may be lower than is widely believed, being of the order of $50 \%$. This is an estimate more in line with community and primary care samples (van Weel-Baumgarten et al. 2000). It is also strikingly consistent with the only previous study of depressed in-patients that restricted itself to first admission cases. Bland and Orn (1982) conducted a 12 to 18 year follow-up of a cohort of unipolar and bipolar in-patients in Canada, and presented data that, although difficult to interpret, suggested that over $40 \%$ experienced only a single episode of depression.

There are features of Kanai et al.'s study which may have lead to an overly optimistic long-term estimate. While the series has the benefit of regular 'prospective' follow-up (a follow-through design) this carries with it the disadvantages of a high attrition rate and shorter follow-up period. Previous researchers who have achieved high follow-up rates, have found that many of those who fall out of prospective follow-up are precisely those who have poorer outcomes. Kanai et al.'s survival curve may have an artificially flattened tail. Kraepelin (1921) also warned that we should not ignore the fact that in almost $20 \%$ of his cases the well interval amounted to 10 years or more. But even making allowances for these possible artefacts, the implication seems to be that a substantial minority, and maybe as many as $50 \%$, of patients presenting to psychiatrists with depression will experience only a single episode. This is a very important and positive message for clinicians and patients alike.

\section{NO IMPROVEMENT IN RECURRENCE RATES OVER 15 YEARS ?}

It does appear that one way of improving the outcome of depression is to conduct more methodologically sound investigations. But there is an important sense in which this leads us away from 
the important challenge of the substantial number of patients who do show a recurrent pattern. In this respect the paper by Kennedy et al. in this issue is also highly informative. Although the Cambridge study relies on a single retrospective follow-up, it uses standardized instruments, and has the advantages of longer duration and more complete follow-up, and it gives a broader account of global treatment and outcome that can be compared directly with previous studies. The authors acknowledge that their cohort is biased towards recurrent cases $(66 \%)$, but the sample is remarkably similar to both the NIMH (62\% with previous episodes) and Edinburgh $(63 \%)$ cohorts. While the bias towards recurrence must colour the outcome in a pessimistic way, the results do perhaps describe more accurately the experience of those who encounter the more severe forms of depression in general psychiatric practice. The majority of the patients they find in their clinics and on their wards do already show a recurrent pattern and the absolute risks for this group do often seem to be much closer to the $50 \%$ 3-year recurrence risks found by Kennedy et al. as against the $50 \%$ lifetime risks seen by Kanai et al.

As the Cambridge cohort is so strikingly similar to those of the NIMH and Edinburgh studies in terms of baseline characteristics, and many of the standardized measures are the same, this gives a unique opportunity to explore whether there have been improvements in outcome over time. Kennedy et al. rightly point out that their study provides little if any evidence that modern treatments are impacting on the frequency of recurrence of depressive disorders. Their survival curves of recurrence differ very little from those in the Edinburgh (Surtees \& Barkley, 1994) and NIMH (Mueller et al. 1999) series that had been ascertained 15 and 10 years previously.

Given their negative findings regarding improvements in recurrence rates, Kennedy et al. are understandably cautious about claiming any better outcome for their series compared with earlier studies. But their report does offer some grounds for optimism. They describe impressive levels of continuing treatment and engagement with services, which are in sharp contrast with the London series 25 years previously. Levels of functioning at follow-up in all domains are also much higher than those reported in London. There is also a one-third increase in those achieving a very good global outcome when measured against the otherwise similar Edinburgh series ascertained 15 years before. Although the total number of deaths is small, the suicide rate of 2.9 per 1000 person years is also notably lower than those reported in the London $(5 \cdot 6)$ Sydney $(4 \cdot 0)$ and Edinburgh $(7 \cdot 3)$ cohorts. Thus, although better treatments may not yet be impacting on the frequency of episodes, there is some evidence that they may be modifying them and ameliorating some of their more disabling and enduring consequences.

\section{NO CHANGE IN RISKS OF PROLONGED EPISODES}

One alarming aspect of all recent follow-up studies of depression has been the consistent proportion of patients who show very prolonged episodes. Previous studies have shown a $20 \%$ chronicity (2-year duration) rate with about half of these persisting for much longer periods (up to 15 years). Kennedy et al. (2003) find similar rates in Cambridge and a separate report (Furukawa et al. 2000) from the Japanese cohort replicates this picture. The fact that both a high and a low recurrent sample show the same pattern adds further weight to Keller \& Boland's view (1998) that each new episode of depression brings with it a renewed and considerable risk of further chronicity. Although textbooks and clinical guidelines abound with treatment algorithms for resistant cases of depression, as yet there appears to have been little progress in translating these into therapeutic gains in general clinical practice.

\section{PREDICTING RECURRENCE}

If recurrence is one crucial determinant of poor outcome in depression, achieving its effect by multiplying the cumulative risk of chronicity and also by compounding secondary and tertiary handicap, then its prediction should become a central goal in order to target scarce resources.

Two powerful predictors of future depressive recurrence have emerged consistently from followup research, and both of these are identified again in the studies published in this issue. The first 
is the presence of residual symptoms after apparent recovery (indicated by Hamilton Depression Rating Scale scores $\geqslant 8$ ). This pattern, which has been found in up to one-third of episodes, predicts a threefold increase in the risk of recurrence (Paykel et al. 1995; Judd et al. 1998). Judd et al. (1998) estimate the absolute magnitude of this risk as $75 \%$ within 2 years and argue that residual symptoms appear to indicate the first steps of a more severe, relapsing, and chronic course (Judd et al. 2000).

Secondly, just as nothing predicts the future like the past, the presence of previous episodes of depression increases the risk of further episodes two-fold (Kennedy et al. 2003). The absolute magnitude of such a risk is highlighted by the NIMH reports in which those with a previous history of depressive episodes had a $59 \%$ chance of another episode within 2 years, and each additional recurrence increased the risk of yet another episode by a further 16\% (Solomon et al. 2000).

Other candidates for the prediction of higher risk of recurrence have previously been identified as including the presence of psychotic features (Coryell et al. 1996), melancholic or somatic features (Duggan et al. 1991), treatment with ECT (O'Leary \& Lee, 1996), having a first-degree relative admitted with depression (Duggan et al. 1998) and low self-confidence on recovery (Surtees \& Wainwright, 1996). The evidence for these factors is weaker and less consistent across studies. Interestingly, none emerge in the Kennedy et al. or Kanai et al. investigations, though the authors acknowledge that small numbers within subgroups may have obscured important effects.

\section{CHALLENGES FOR CLINICIANS AND THE RESEARCH COMMUNITY}

The failure of Kennedy et al. to demonstrate reductions in actual recurrence rates despite the availability of modern pharmacological and psychological treatments poses a challenge for those who advocate long-term prophylactic strategies. As the authors of both the Japanese and the Cambridge papers observe there is now good evidence for the efficacy of both long-term drug and psychological treatments in reducing recurrence rates by a factor of about $50 \%$, though much of this is derived from studies that do not extend beyond 2 or at most 3 years (Geddes et al. 2003). But it is clear that translating this therapeutic potential into effectiveness in clinical settings is a significant problem.

The effectiveness of an established maintenance treatment depends on a range of factors in both patients and health practitioners. Patients dislike drugs which they feel are controlling their mood, and they are also alienated by perceived connotations of chronic illnesses when taking long-term treatments. Side-effects such as sexual dysfunction, which may be tolerable in the shorter term can become ever more of a disincentive until eventually a drug is discontinued. Professionals too may be reluctant to sustain troublesome and often costly treatments in the face of apparent recovery, and the necessary investment in long-term monitoring and encouragement may be hard to prioritize in the face of competing demands on scarce resources. Skilled cognitive behaviour therapy (CBT) is not yet routinely available in UK practice, and even where it is patients may be reluctant to invest in time-consuming treatments which seem to have only limited relevance to their current states of apparent recovery.

The problem in sustaining long-term protective treatments is compounded by growing evidence that although prophylactic strategies postpone the risks of recurrence they do not reduce them in the longer term. Thus, when an antidepressant is discontinued, even after an interval of several years, the risk of recurrence in the next year reverts to that of the previous high risk period. For those with an already recurrent pattern this remains of the order of $50 \%$ (Kupfer et al. 1992; Viguera et al. 1998). Equally, the protective effects of CBT appear to wear off after 4 years with risks returning to pre-treatment levels (Fava et al. 1998).

\section{FUTURE DIRECTIONS}

Do we need further outcome research in depressive disorders? There is still a shortage of well conducted prospective follow through studies of first episodes, ascertained at various levels from community through primary care and secondary care to in-patient settings, so as to be fully representative. These need to be conducted for longer periods and to achieve better follow-up rates. 
They will be expensive and difficult to resource, and will require considerable efforts to engage and maintain a full range of depressed patients in the enterprise. The goals will be to establish baseline rates and if possible identify a good prognosis group. These patients could then be spared long-term interventions, and this would represent a very significant benefit.

There should also be renewed support for effectiveness studies of strategies to manage resistant depression, coupled with considerable investment in developing innovative treatments for this group. It is likely that addressing co-morbidity such as anxiety, substance misuse, and personality difficulties will play a crucial role here.

At a clinical level, there would be great value in a widespread programme to identify those patients with residual symptoms after apparent recovery. This could be combined with an exploration of strategies to treat these symptoms, followed by pragmatic trials evaluating the effectiveness of this approach in reducing recurrence in the longer term. We must find ways to identify those at very high risk of recurrent depressive disorders at an early stage in their illness careers. Investigating and clarifying risk factors for further recurrence will allow the identification of high risk cohorts for further targeting of scarce resources.

There is an urgent need to implement more widely the best current practices for managing recurrent depression incorporating the four arms of preventative treatment; psycho-education, pharmacotherapy, enhancing concordance and psychotherapy. The effectiveness of these approaches also needs continuing evaluation in pragmatic trials, beginning sensibly with cohorts of patients in high risk groups.

Finally, we are challenged to develop new strategies for long-term treatment. These are likely to be more radical than merely a continuation of the short-term measures such as antidepressants which still appear to be serving us in less than ideal ways. More of the same may well not be the solution. Perhaps we have been naïve to suppose that it would be so?

A LAN S. LEE

\section{REFERENCES}

Bland, R. C. \& Orn, H. (1982). Course and outcome in affective disorders. Canadian Journal of Psychiatry 27, 573-578.

Coryell, W., Leon, A., Winoker, G., Endicott, J., Keller, M., Akiskal, H. \& Solomon, D. (1996). Importance of psychotic features to long-term course in major depressive disorder. American Journal of Psychiatry 153, 483-489.

Duggan, C., Lee, A. S. \& Murray, R. M. (1991). Do different subtypes of hospitalized depressives have different outcomes? Archives of General Psychiatry 48, 308-312.

Duggan, C., Sham, P., Minne, C., Lee, A. S. \& Murray, R. M. (1998). Family history as a predictor of poor long-term outcome in depression. British Journal of Psychiatry 173, 527-530.

Fava, G. A., Rafanelli, C., Grandi, S., Canestrari, R. \& Morphy, M. A. (1998). Six year outcome for cognitive behavioral treatment of residual symptoms in major depression. American Journal of Psychiatry 155, 1443-1445.

Furukawa, T. A., Kitamura, T. \& Takahashi, K. (2000). Time to recovery of an inception cohort with hitherto untreated unipolar major depressive episodes. British Journal of Psychiatry $\mathbf{1 7 7}$ 331-335.

Geddes, J. R., Carney, S., Davies, C., Furukawa, T. A., Kupfer, D. J., Frank, E. \& Goodwin, G. M. (2003). Relapse prevention with antidepressant drug treatment in depressive disorders: a systematic review. Lancet 361, 653-661.

Judd, L. L., Akiskal, H. S., Maser, J. D., Zeller, P. J., Endicott, J., Coryell, W., Paulus, M. P., Kunovac, J. L., Leon, A. C., Mueller, T. I., Rice, J. A. \& Keller, M. B. (1998). Major depressive disorder: a prospective study of residual subthreshold symptoms as predictor of rapid relapse. Journal of Affective Disorders $\mathbf{5 0}$, 97-108.

Judd, L. L., Paulus, M. P., Schettler, P. J., Akiskal, H. S., Endicott, J., Leon, A. C., Maser, J. D., Mueller, T., Solomon, D. A. \& Keller, M. B. (2000). Does incomplete recovery from first lifetime major depressive episode herald a chronic course of illness? American Journal of Psychiatry 157, 1501-1504.

Kanai, T., Takeuchi, H., Furukawa, T. A., Yoshimura, R. Imaizumi, T., Kitamura, T. \& Takahashi, K. (2003). Time to recurrence after recovery from major depressive episodes and its predictors. Psychological Medicine 33, 839-845.

Keller, M. B. \& Boland, R. J. (1998). Implications of failing to achieve successful long-term maintenance treatment of recurrent unipolar major depression. Biological Psychiatry 44, 348-360.

Keller, M. B., Klerman, G. L., Lavori, P. W., Coryell, W., Endicott, J. \& Taylor, J. (1984). Long-term outcome of episodes of major depression: clinical and public health significance. Journal of the American Medical Association 252, 788-792.

Kennedy, N., Abbott, R. \& Paykel, E. S. (2003). Remission and recurrence of depression in the maintenance era: long-term outcome in a Cambridge cohort. Psychological Medicine 33, 827-838.

Kiloh, L. G., Andrews, G. \& Neilson, M. (1988). The long-term outcome of depressive illness. British Journal of Psychiatry 153, 752-757.

Kraepelin, E. (1921). Manic-Depressive Insanity and Paranoia. (Translated into English by R. M. Barclay from the 8th edn. of Lehrbuch der Psychiatrie, Vols. III and IV). E. \& S. Livingstone: Edinburgh.

Kupfer, D. J., Frank, E., Perel, J. M., Cornes, C., Mallinger, A. G., Thase, M. E., McEachran, A. B. \& Grochocinski, V. J. (1992). Five year outcome for maintenance therapies in recurrent depression. Archives of General Psychiatry 49, 769-773.

Lee, A. S. \& Murray, R. M. (1988). The long-term outcome of Maudsley depressives. British Journal of Psychiatry 153, 741-751.

Mueller, T. I., Leon, A. C., Keller, M. B., Solomon, D. A., Endicott, J., Coryell, W., Warshaw, M. \& Maser, J. D. (1999). Recurrence after recovery from major depressive disorder during 15 years of observational follow-up. American Journal of Psychiatry 156, $1000-1006$ 
O'Leary, D. A. \& Lee, A. S. (1996). Seven year prognosis in depression. Mortality and readmission risk in the Nottingham ECT cohort. British Journal of Psychiatry 169, 423-429.

Paykel, E. S. (1994). Historical overview of outcome of depression. British Journal of Psychiatry 165 (suppl. 26), 6-8.

Paykel, E. S., Ramana, R., Cooper, Z., Hayhurst, H., Kerr, J. \& Barocka, A. (1995). Residual symptoms after partial remission: an important outcome in depression. Psychological Medicine 25, 1171-1180.

Solomon, D. A., Keller, M. B., Leon, A. C., Mueller, T. I., Lavori, P. W., Shea, M. T., Coryell, W., Warshaw, M., Turvey, C., Maser, J. D. \& Endicott, J. (2000). Multiple recurrences of major depressive disorder. American Journal of Psychiatry 157, 229-233.
Surtees, P. G. \& Barkley, C. (1994). Future imperfect: the long-term outcome of depression. British Journal of Psychiatry 164, 327-341.

Surtees, P. G. \& Wainwright, N. W. J. (1996). Fragile states of mind: neuroticism, vulnerability and the long-term outcome of depression. British Journal of Psychiatry 169, 338-347.

Viguera, A. C., Baldessarini, R. J. \& Friedberg, J. (1998). Discontinuing antidepressant treatment in major depression. Harvard Review of Psychiatry 5, 293-306.

van Weel-Baumgarten, E. M., Schers, H. J., van den Bosch, W. J., van den Hoogen, H. J. \& Zitman, F. G. (2000). Long-term followup of depression amongst patients in the community and in family practice settings: a systematic review. Journal of Family Practice 49, 1113-1120. 